\title{
Neuromodulation in refractory epilepsy: Brazilian specialists consensus
}

\author{
Neuromodulação em epilepsia refratária: consenso dos especialistas brasileiros \\ Vera Cristina Terra ${ }^{1}$, Isabella D'Andrea-Meira ${ }^{1}$, Ricardo Amorim², Francisco Arruda ${ }^{1}$, Andrea Julião de \\ Oliveira1', Luciano De Paola', Adélia Maria de Miranda Henriques-Souza,
}

\begin{abstract}
Epilepsy is a potentially devastating brain disorder characterized by a predisposition to spontaneous epileptic seizures. In patients with medically refractory epilepsy, new non-pharmacological therapeutic approaches may be considered. In this scenario, palliative surgery such as vagus nerve stimulation (VNS) or deep brain stimulation (DBS) may be indicated in a subset of patients. In this paper we make recommendations for the use of VNS and DBS in patients in Brazil with refractory epilepsy.
\end{abstract}

Keywords: vagus nerve stimulation; deep brain stimulation; epilepsy.

\section{RESUMO}

Epilepsia é uma doença cerebral potencialmente devastadora caracterizada por predisposição em gerar crises epilépticas espontâneas. Em pacientes com epilepsia refratária novas abordagens terapêuticas, não farmacológicas, podem ser consideradas. Neste cenário, cirurgias paliativas, como a estimulação do nervo vago (VNS) ou estimulação cerebral profunda (DBS) podem ser indicadas em um subgrupo de pacientes. Neste trabalho sugerimos recomendações sobre as indicações de uso do VNS e do DBS em pacientes com epilepsia refratária no Brasil.

Palavras-chave: estimulação do nervo vago; estimulação encefálica profunda; epilepsia.

Epilepsy is a potentially devastating brain disorder characterized by a predisposition to spontaneous epileptic seizures, defined as the occurrence of two unprovoked seizures or one unprovoked seizure with a high probability of recurrence or an epileptic syndrome ${ }^{1}$. In the United States, the incidence and prevalence of epilepsy are 48.7/100,000 and 5.7/1,000 inhabitants, respectively, while in South America the prevalence is estimated to be twice as high ${ }^{2}$.

Antiepileptic drugs (AEDs) remain the therapeutic pillar for epilepsy, however, even the best clinical treatment is doomed to fail in about $20 \%$ to $40 \%$ of patients. These cases are considered refractory, a definition that requires patients to have failed two adequate trials of appropriately-chosen $\mathrm{AEDs}^{3}$.

People with uncontrolled epilepsy are subjected to many dire consequences, such as falls and the resulting lesions, driving restrictions, work limitations, lack of independence, the need of constant supervision, frequent medical consultations, hospital admissions and medically-related expenses. These result in a significant impact on the quality of life, leading to school absenteeism, unemployment (5-6 times higher than the general population), depression (50-70\% prevalence in temporal lobe epilepsy) and other psychiatric conditions, such as generalized anxiety disorder and phobic disorder (56\%), often leading to social isolation ${ }^{4}$ and even suicide.

Although $25 \%$ of patients with epilepsy may be candidates for a surgical approach, a significant portion of them may not benefit from this type of intervention. In such cases, a variety of alternative approaches may be considered, including neuromodulation. The latter is a therapeutic modality that uses electrical or magnetic stimulation inducing short- and long-term modifications in the nervous system circuits. Three types of implantable neurostimulation devices have been introduced and approved for the management of refractory epilepsy: vagus nerve stimulation (VNS), deep brain stimulation (DBS), and responsive neurostimulation systems $(\mathrm{RNSs})^{5,6}$.

'Liga Brasileira de Epilepsia, Comissão de Neuromodulação, São Paulo SP, Brasil;

${ }^{2}$ Academia Brasileira de Neurologia, Departamento Científico de Epilepsia, São Paulo SP, Brasil.

Correspondence: Vera Cristina Terra; Epicentro - Hospital Nossa Senhora das Graças; Rua Prof. Rosa Saporski, 229 / 30 andar; 80810 -120 Curitiba PR, Brasil; E-mail:v.c.terra@gmail.com

Conflict of interest: There is no conflict of interest to declare.

Received 16 June 2016; Accepted 01 September 2016. 


\section{VAGUS NERVE STIMULATION}

Currently, more than 100,000 VNS devices have been implanted in more than 80,000 patients 7 . In Brazil, from January 2001 to March 2016, 665 VNS devices were implanted (Politec Health, personal communication).

The vagus nerve stimulator has been approved in Europe (1994), USA (1997) and Brazil (2000) as adjunctive treatment for refractory focal epilepsies to help in reducing the frequency and severity of seizures in patients who are not candidates for conventional surgical treatment. In Brazil, VNS therapy is approved by ANVISA (Agência Nacional de Vigilância Sanitária, or the National Health Agency) for use in patients, at any age, who have been diagnosed with refractory, focal or generalized epilepsy for two or more years.

This device chronically and intermittently stimulates preferentially the left cervical vagus nerve, leading to a reduction in seizure frequency and/or intensity. It is commonly estimated that one year following implantation $52.1 \%$ of patients show a seizure frequency reduction of at least $50 \%^{8}$. That is frequently accompanied by a potential improvement in mood and alertness, as well as verbal skills, memory, and academic and overall professional performance. Interestingly, these relevant effects may be independent of the reduction in seizure frequency, since similar improvements are reported even in patients in whom seizure reduction is not observed'.

A number of mechanisms of action have been proposed to try and explain the antiepileptic action of VNS. Structures such as the basal ganglia and thalamus are likely to play an important role via the interference in the electrical brain network leading to desynchronization of cortical electrical activity $^{10}$. In support of this hypothesis, studies show that cutaneous stimulation of vagal afferent fibers and other sensory pathways affect EEG synchrony and sleep cycles ${ }^{11}$.

The adverse effects are rather low at about $2 \%$, usually occuring during the "on" phase of stimulation, and have a tendency to decrease over time. The most common complications are postoperative hematoma, infection, and vocal cord paralysis? ${ }^{7}$ Voice hoarseness, cough and paresthesias can also occur?

\section{DEEP BRAIN STIMULATION}

Deep brain stimulation involves the delivery of a current to the brain parenchyma through deeply implanted electrodes, targeting the anterior nucleus of the thalamus, median nucleus of the thalamus, cerebellar nucleus and others. Over the last decade, a series of preclinical and clinical studies have shown that DBS in the anterior nucleus of the thalamus reduces seizure rates and increases the latency for the development of seizures and status epilepticus ${ }^{12}$.
Knowledge of the basic mechanisms of DBS and of the optimal stimulation parameters is limited. It is postulated that DBS either disrupts or inhibits epileptiform activity around the epileptogenic thalamocortical networks ${ }^{13}$. This action is mediated by crucial nodes in the epileptogenic network, such as the anterior nucleus of the thalamus (with its wide limbic and cortical connections), regions involved in sustaining, propagating, or triggering epileptic activity and promoting its inhibition. Even less is known about possible side effects of DBS of the anterior nucleus of the thalamus on cognition and emotion. Optimizing therapeutic effects and minimizing side effects require adjustment of DBS parameters according to knowledge of the therapeutic efficacy, as well as the DBS effects on emotion and cognition ${ }^{14}$.

The Sante study showed many interesting results during their long-term follow-up after DBS implantation, like: a reduction of $40 \%$ seizure from baseline at one year and $69 \%$ at five years; The responder rate $(\geq 50 \%$ reduction in seizure frequency) at one year was $43 \%$, and $68 \%$ at five years; At the five-year follow-up, $16 \%$ of subjects had been seizure-free for at least six months; There were no reported unanticipated adverse device effects or symptomatic intracranial hemorrhages; And the Liverpool Seizure Severity Scale and 31-item Quality of Life in Epilepsy scores showed statistically significant improvement over baseline, both at one year and at five years follow-up $(\mathrm{p}<0.001)^{15}$. The most serious potential side effects of DBS for epilepsy are death, infection, hemorrhage, and status epilepticus. These did not materialize in higher than expected numbers in the SANTE study ${ }^{16}$. More so, the figures for significant side effects in DBS for epilepsy treatment do not differ significantly compared to the DBS implantation in parkinsonian patients ${ }^{17}$.

In Brazil, DBS therapy is approved by ANVISA for use in patients with epilepsy who have used VNS without significant improvement for at least two years.

\section{RECOMMENDATIONS FOR VNS AND DBS USE}

The aim of this paper is to revise general guidelines for VNS therapy previously published in $2013^{18}$ and establish indications for DBS.

Taking into account the available data, the Neuromodulation Committee for the Brazilian League of Epilepsy (Brazilian Chapter of the International League Against Epilepsy) and the Scientific Department of Epilepsy of the Brazilian Academy of Neurology (Brazilian Chapter of the World Federation of Neurology) suggest that VNS and DBS may be considered as an option for patients with refractory epilepsy at any age, including children ${ }^{19}$ and adults, following an evaluation by a neurologist, child neurologist or neurophysiologist with experience in epilepsy and in concordance with the case scenarios listed below. 


\section{For VNS use, patients should meet the following} criteria

1) Failed to achieve seizure freedom following adequate trials (whether in monotherapy or combined regime) of two tolerated and appropriately chosen and used first-generation AEDs (e.g. phenobarbital, phenytoin, carbamazepine, valproic acid $)^{3}$, plus an additional trial with at least one second or third-generation AED (e.g. oxcarbazepine, lamotrigine, topiramate, vigabatrin, clobazam, levetiracetam and lacosamide), meeting the definition of clinically refractory epilepsy and determining the referral to a specialized epilepsy center.

2) A comprehensive evaluation conducted at a tertiary or higher level epilepsy center should exclude the option for resective surgery, including the use of invasive recording if indicated.

3) Refusal to pursue a resective surgery after a full explanation of risks and benefits of the proposed procedure and thorough explanation regarding the VNS option and its own risks and benefits.

\section{Special situations}

Although there is no formal indication for VNS therapy in the following special clinical situations, it may be considered in patients presenting with:

1) Idiopathic generalized epilepsy nonresponsive to broad spectrum AEDs, i.e., levetiracetam, valproic acid and lamotrigine;

2) Progressive myoclonic epilepsy;

3) Genetic/metabolic epilepsies;

4) Super-refractory status epilepticus ${ }^{20}$.

\section{For DBS use, patients should meet the following criteria}

1) Remain refractory after the use of VNS for two years, with suitable adjustments and without improvement both in seizure frequency and intensity, i.e., less than $50 \%$ improvement.

2) This lack of improvement should be confirmed through adequate assessment performed by a trained epileptologist.

3) If indicated, the device must be implanted by a neurosurgeon with proven experience in neurofunctional surgery, at an institution suitable for high complexity procedures, including full access to CT-scan, MRI 1.5 T or higher, neuronavigation and robotic assistant.

\section{RECOMMENDATIONS FOR VNS ADJUSTMENT AND MANAGEMENT}

Vagus nerve stimulation parameters must be adjusted individually by the patient's attending physician, taking into account seizure control and adverse effects, almost as if VNS therapy were an add-on drug in the treatment of epilepsy. The VNS generator is usually turned on one to two weeks after implantation. The initial current is typically set to $0.25 \mathrm{~mA}$, followed by increments of $0.25 \mathrm{~mA}$ every two weeks. Faster titration may be attempted, if necessary, according to patient's tolerance. Typical current values for a satisfactory response usually lie between $1.5 \mathrm{~mA}$ and $2.5 \mathrm{~mA}$ - ranging from 0.5 $\mathrm{mA}$ to $3.5 \mathrm{~mA}$ - and are usually reached between two to four months after implantation ${ }^{21}$.

Once a satisfactory output current has been reached, other stimulation parameters may be changed - particularly the duty cycle, i.e., on-time/off-time - in an attempt to optimize seizure control. These further changes should be done at longer intervals (every two to three months) to allow better appreciation of the response. Thus, duty cycles may be changed, with shorter duration of stimulation, at shorter intervals. Some reports suggest that, although conventional duty cycles are more effective than rapid cycles in the initial treatment, non-responders may experience significant improvement in seizure control when the duty cycle is increased ${ }^{22}$.

Other parameters such as stimulus frequency and pulse duration may be changed in order to favor tolerance. Thus, stimulus frequency - which ranges between $1 \mathrm{~Hz}$ and $30 \mathrm{~Hz}$ - is usually set at $30 \mathrm{~Hz}$, but may be reduced to $20 \mathrm{~Hz}$, and pulse width - ranging between $130 \mu$ sec and $1000 \mu \mathrm{sec}$ - is usually set at $500 \mu \mathrm{sec}$, but may be reduced to $250 \mu \mathrm{sec}$, whenever adverse effects are reported ${ }^{21}$.

Finally, every visit should include measuring the remaining battery of the generator and testing the integrity of the system, by measuring the impedance of the circuit. This is particularly important in long-term follow-up, since patients tend to reduce the frequency of their visits once the parameters have been established, and often forget that the battery will eventually run out. Most currently used VNS models have batteries that last anywhere between four and 10 years - varying according to the energy spent - i.e., value of the output current, duty cycle and frequency of use of the magnet ${ }^{23}$.

\section{Final remarks}

After careful review of the current literature this committee reached the following conclusions:

1) Vagus nerve stimulation and DBS represent valid neuromodulation tools and, in that order, could be included as treatment options for medically refractory epilepsy patients (both children and adults) who are not suitable for or do not wish to have resective surgery.

2) The indication for VNS or DBS implant should be determined by experienced epileptologists (neurologists, child neurologists and neurophysiologists) after refractory epilepsy confirmation and surgical ward off possibility in a tertiary epilepsy center.

3) The surgery for VNS or DBS implantation should be conducted by functional neurosurgeons, with proven experience.

4) Patients must fully acknowledge the risks and benefits of either of the neuromodulation therapies discussed herein and, in particular, the somewhat limited expectations in rendering these patients completely seizure-free. 
1. Fisher RS, Acevedo C, Arzimanoglou A, Bogacz A, Cross JH, Elger CE et al. ILAE official report: a practical clinical definition of epilepsy. Epilepsia. 2014;55(4):475-82. doi:10.1111/epi.12550

2. Hauser WA., Annegers JF, Kurland LT. Incidence of epilepsy and unprovoked seizures in Rochester, Minnesota: 1935-1984. Epilepsia. 1993;34(3):453-68. doi:10.1111/j.1528-1157.1993.tb02586.x

3. Kwan P, Arzimanoglou A, Berg AT, Brodie MJ, Allen Hauser W, Mathern $G$ et al. Definition of drug resistant epilepsy: consensus proposal by the ad hoc Task Force of the ILAE Commission on Therapeutic Strategies. Epilepsia. 2010;51(6):1069-77. doi:10.1111/j.1528-1167.2009.02397.x

4. Chavel SM, Westerveld M, Spencer S. Long-term outcome of vagus nerve stimulation for refractory partial epilepsy. Epilepsy Behav. 2003;4(3):302-9. doi:10.1016/S1525-5050(03)00109-4

5. Cox JH, Seri S, Cavanna AE. Clinical utility of implantable neurostimulation devices for uncontrolled seizures. Neuropsychiatr Dis Treat. 2014:10:2191-200. doi:10.2147/NDT.S60854

6. Chkhenkeli SA, Sramka M, Lortkipanidze GS, Rakviashvili TN, Bregvadze ES, Magalashvili GE et al. Electrophysiological effects and clinical results of direct brain stimulation for intractable epilepsy. Clin Neurol Neurosurg. 2004;106(4):318-29. doi:10.1016/j.clineuro.2004.01.009

7. Révész D, Rydenhag B, Ben-Menachem E. Complications and safety of vagus nerve stimulation: 25 years of experience at a single center.J Neurosurg Pediatr. 2016;25:18(1):97-104. doi:10.3171/2016.1.PEDS15534

8. Elliott RE, Morsi A, Tanweer O, Grobelny B, Geller E, Carlson C et al. Efficacy of vagus nerve stimulation over time: review of 65 consecutive patients with treatment-resistant epilepsy treated with VNS $>10$ years. Epilepsy Behav. 2011;20(3):478-83. doi:10.1016/j.yebeh.2010.12.042

9. McLachlan RS, Sadler M, Pillay N, Guberman A,Jones M, Wiebe S et al. Quality of lige after vagus nerve stimulation for intractable epilepsy: is seizure control the only contributing factor? Eur Neurol. 2003;50:16-9. doi:10.1159/000070853

10. Zabara J. Inhibition of experimental seizures in canines by repetitive vagal stimulation. Epilepsia 1992;33(6):1005-12. doi:10.1111/j.1528-1157.1992.tb01751.x

11. Rutecki P. Anatomical, physiological, and theoretical basis for the antiepileptic effect of vagus nerve stimulation. Epilepsia. 1990;31(s2):S1-6. doi:10.1111/j.1528-1157.1990.tb05843.x

12. Covolan L, Almeida AC, Amorim B, Cavarsan C, Miranda MF, Aarão MC et al. Effects of anterior thalamic nucleus deep brain stimulation in chronic epileptic rats. PLoS One. 2014;9(6):e97618. doi:10.1371/journal.pone.0097618
13. Gooneratne IK, Green AL, Dugan P, Sen A, Franzini A, Aziz T, Cheeran B. Comparing neurostimulation technologies in refractory focal-onset epilepsy. $J$ Neurol Neurosurg Psychiatry. 2016 Nov;87(11):1174-1182. doi: 10.1136/jnnp-2016-313297.

14. Morace R, DI Gennaro G, Quarato P, D’Aniello A, Amascia A, Grammaldo $L$ et al. Deep brain stimulation for intractabile epilepsy. J Neurosurg Sci. 2016 Jun;60(2):189-98.

15. Salanova V, Witt T, Worth R, Henry TR, Gross RE, Nazzaro $\mathrm{JM}$ et al. Long-term efficacy and safety of thalamic stimulation for drug-resistant partial epilepsy. Neurology. 2015;84(10):1017-25. doi:10.1212/WNL.0000000000001334

16. Fisher R, Salanova V, Witt T, Worth R, Henry T, Gross R et al. Electrical stimulation of the anterior nucleus of thalamus for treatment of refractory epilepsy. Epilepsia. 2010;51(5):899-908. doi:10.1111/j.1528-1167.2010.02536.x

17. Sprengers M, Vonck K, Carrette E, Marson AG, Boon P. Deep brain and cortical stimulation for epilepsy [Review]. Cochrane Database Syst Rev. 2014;6(6): CD008497. doi:10.1002/14651858.CD008497.pub2

18. Terra VC, Amorim R, Silvado C, Oliveira AJ, Jorge CL, Faveret E et al. Vagus nerve stimulator in patients with epilepsy: indications and recommendations for use. Arq Neuropsiquiatr. 2013;71(11):902-6. doi:10.1590/0004-282X20130116

19. Fernandez L, Gedela S, Tamber M, Sogawa Y. Vagus nerve stimulation in children less than 3 years with medically intractable epilepsy. Epilepsy Res. 2015;112(112):37-42. doi:10.1016/j.eplepsyres.2015.02.009

20. Bayrlee A, Ganeshalingam N, Kurczewski L, Brophy GM. Treatment of super-refractory status epilepticus. Curr Neurol Neurosci Rep. 2015;15(10):66. doi:10.1007/s11910-015-0589-2

21. Takamichi Y. Vagus nerve stimulation therapy: indications, programing, and outcomes. Neurol Med Chir. 2015;55(5):407-15. doi: 10.2176/nmc.ra.2014-0405

22. DeGiorgio C, Heck C, Bunch S, Britton J, Green P, Lancman M et al. Vagus nerve stimulation for epilepsy: randomized comparison of three stimulation paradigms. Neurology. 2005;65(2):317-9. doi:10.1212/01.wnl.0000168899.11598.00

23. Vonck K, Dedeurwaerdere S, De Groote L, Thadani V, Claeys P, Gossiaux F et al. Generator replacement in epilepsy patients treated with vagus nerve stimulation. Seizure. 2005 Mar;14(2): 89-99. doi:10.1016/j.seizure.2004.11.001 